\title{
Teste de deterioração controlada em sementes de maxixe
}

\author{
Salvador B. Torres
}

EMPARN, C. Postal 188, 59062-500 Natal-RN; Bolsista CNPq; E-mail: sbtorres@ digizap.com.br

\begin{abstract}
RESUMO
O potencial fisiológico de sementes, determinado pela germinação e vigor, é diretamente responsável pelo desempenho das sementes em campo, refletindo dessa forma na produtividade de diversas espécies de hortaliças de importância econômica. Diante disso, a pesquisa teve como objetivo estudar a metodologia do teste de deterioração controlada, procurando-se verificar sua eficiência para identificação de diferentes níveis de vigor de lotes de sementes de maxixe (Cucumis anguria L.), cv. Liso. Para tanto, cinco lotes de sementes foram submetidos aos testes de germinação, emergência de plântulas em casa de vegetação, envelhecimento acelerado com solução saturada de $\mathrm{NaCl}$, condutividade elétrica e deterioração controlada (sementes com graus de umidade de $19 ; 21$ e $24 \%$, a $45^{\circ} \mathrm{C}$, durante 24 e 48 horas). A combinação $24 \%$ de água $/ 24 \mathrm{~h} / 45^{\circ} \mathrm{C}$ no teste de deterioração controlada mostrou-se eficiente para detectar diferenças de vigor entre os lotes de sementes de maxixe.
\end{abstract}

Palavras-chave: Cucumis anguria, potencial fisiológico, vigor.

\begin{abstract}
Controlled deterioration test on gherkin seeds

Research has emphasized the relationship of standard germination test and vigor on seedling emergence and stand establishment. In contrast, information relating seed vigor to plant performance is less available. The controlled deterioration as a means to evaluate the vigor of gherkin seeds was studied. Five lots of cultivar Liso were submitted to tests of germination, greenhouse seedling emergence, accelerated aging with saturated solution of $\mathrm{NaCl}$, electrical conductivity and controlled deterioration (19;21 and 24\% water content, at $45^{\circ} \mathrm{C}$, for 24 and 48 hour periods). The $24 \%$ water content $/ 24 \mathrm{~h} / 45^{\circ} \mathrm{C}$ combination, for the controlled deterioration test, was efficient to detect vigor differences between gherkin seed lots.
\end{abstract}

Keywords: Cucumis anguria, physiological potential, vigor.

(Recebido para publicação em 31 de maio de 2004 e aceito em 26 de janeiro de 2005)

$\mathrm{A}$ tualmente a utilização de métodos rápidos, confiáveis e de fácil execução para estimar a viabilidade das sementes, é uma necessidade nas instituições de pesquisas, empresas e laboratórios de análises de sementes. No entanto, para as muitas espécies olerícolas, como o maxixe, a pesquisa ainda não oferece metodologias apropriadas para avaliar o vigor das sementes.

Os testes de vigor das sementes têm como objetivo básico a identificação de diferenças importantes na qualidade fisiológica dos lotes, principalmente dos que possuem poder germinativo semelhante (MARCOS-FILHO, 1999). Portanto, com o uso de testes de vigor, pretende-se distinguir lotes com maior ou menor probabilidade de apresentar bom desempenho após a semeadura e/ou durante o armazenamento. Vários são os testes disponíveis para grandes culturas, mas maiores estudos são necessários para espécies olerícolas. O teste de deterioração controlada, inicialmente desenvolvido para a avaliação do vigor de lotes de sementes de hortaliças, como cenoura, cebola, alface e brássicas (POWELL; MATTHEWS, 1981), procurando obter informações referentes ao potencial de armazenamento (MATTHEWS; POWELL, 1987), cons- titui-se em uma técnica de envelhecimento similar ao do teste de envelhecimento acelerado, incorporando melhor controle do grau de umidade da semente e da temperatura, durante o período de envelhecimento (KRZYZANOWSKI; VIEIRA, 1999). Neste teste, o grau inicial de umidade das sementes é trazido para um mesmo nível, em todas as amostras antes do início do período de deterioração, em altas temperaturas, ser iniciado (HAMPTON; TEKRONY, 1995). Segundo Powell (1995), este teste é mais apropriado para espécies de sementes pequenas como as de hortaliças, permitindo a manutenção das sementes com grau de umidade uniforme até o final do teste.

Na literatura consultada, alguns trabalhos referentes ao uso de testes de vigor em olerícolas podem ser encontrados, entre eles, com uso da deterioração controlada em sementes de Lactuca sativa L. e Daucus carota L. (MATTHEWS; POWELL, 1987), Brassica oleraceae var. botrytis, var. gemmifera e var. italica (THORNTON; POWELL, 1992; HAMPTON; TEKRONY, 1995; MENDONÇA et al., 2003, respectivamente), tomate (PANOBIANCO; MARCOS-FILHO, 2001) e melão (TORRES, 2002).
Entretanto, verifica-se que este teste, mesmo sendo dirigido para a avaliação do potencial fisiológico de sementes de hortaliças, pouco foi estudado para sementes de maxixe. Diante do exposto, o trabalho objetivou estudar a metodologia do teste de deterioração controlada, procurando-se verificar sua eficiência para identificação de diferentes níveis de vigor de lotes de sementes de maxixe (Cucumis anguria L.).

\section{MATERIAL E MÉTODOS}

O trabalho foi conduzido em laboratório da EMPARN, em Natal, RN. Para isso, utilizaram-se cinco lotes de sementes de maxixe, cultivar Liso, não tratadas quimicamente, provenientes de cinco produtores do Rio Grande do Norte. Após a recepção, as sementes foram homogeneizadas em divisor tipo Solo, e acondicionadas em saco de papel Kraft e armazenadas em condições controladas $\left(18-20^{\circ} \mathrm{C}\right.$ e $60 \%$ de umidade relativa do ar), até o final da fase experimental. As avaliações da qualidade das sementes foram realizadas por meio dos grau de umidade, realizado em estufa a $105 \pm 3^{\circ} \mathrm{C} / 24 \mathrm{~h}$, utilizando-se quatro 
Tabela 1. Qualidade inicial das sementes de maxixe, cultivar Liso, avaliada através do grau de umidade (GU), teste de germinação (TG), emergência de plântulas (EP), envelhecimento acelerado com $\mathrm{NaCl}$ (EA) e condutividade elétrica (CE). Natal, EMPARN, 2004.

\begin{tabular}{|c|c|c|c|c|c|}
\hline \multirow{2}{*}{ Lote } & GU & TG & EP & EA & \multirow{2}{*}{$\begin{array}{c}\mathrm{CE} \\
(\mu \mathrm{mho} / \mathrm{cm} / \mathrm{g})\end{array}$} \\
\hline & \multicolumn{4}{|c|}{$\%$} & \\
\hline 1 & 7,6 & $96 \mathrm{a}$ & 94 a & 92 a & $25,81 \mathrm{a}$ \\
\hline 2 & 7,1 & 96 a & 92 a & 96 a & $23,68 a$ \\
\hline 3 & 7,0 & $88 \mathrm{~b}$ & $86 \mathrm{bc}$ & $80 \mathrm{~b}$ & $45,76 \mathrm{~b}$ \\
\hline 4 & 7,0 & $85 \mathrm{~b}$ & $73 \mathrm{~d}$ & $70 \mathrm{c}$ & $55,25 \mathrm{c}$ \\
\hline 5 & 7,4 & $86 \mathrm{~b}$ & $80 \mathrm{~cd}$ & $72 \mathrm{c}$ & $59,01 \mathrm{c}$ \\
\hline C.V. (\%) & - & 3,5 & 5,8 & 4,6 & 7,5 \\
\hline
\end{tabular}

"Médias seguidas pela mesma letra na coluna não diferem estatisticamente pelo teste de Tukey a $5 \%$

subamostras com cerca de $5 \mathrm{~g}$ para cada lote (BRASIL, 1992); germinação, quatro repetições de 50 sementes foram distribuídas em caixas plásticas tipo gerbox sobre duas folhas de papel mata borrão, umedecidas com água na proporção de 2,5 vezes o peso do papel seco, e colocadas para germinar a $25^{\circ} \mathrm{C}$ sem a presença de luz. As contagens foram realizadas aos quatro e oito dias após a semeadura, segundo os critérios estabelecidos pelas Regras para Análise de Sementes (BRASIL, 1992); condutividade elétrica, conduzido pelo método de massa, com quatro repetições de 50 sementes puras, para cada lote, pesadas com precisão de $0,01 \mathrm{~g}$. Em seguida, cada repetição foi colocada em copo plástico contendo $50 \mathrm{ml}$ de água destilada e mantida à temperatura de $25^{\circ} \mathrm{C}$, por 12 horas (TORRES et al., 1998). As leituras foram realizadas em condutivímetro Digimed DM-31, dotado de ajuste automático da temperatura e, os resultados, expressos em $\mu \mathrm{mhos} / \mathrm{cm} / \mathrm{g}$ de sementes; envelhecimento acelerado, utilizando-se o método gerbox em câmara do tipo BOD; foram colocadas quatro gramas de sementes e $40 \mathrm{ml}$ de solução saturada de $\mathrm{NaCl}(40 \mathrm{~g}$ do sal/100 ml de água) e, posteriormente, levados à câmara de envelhecimento regulada para $41^{\circ} \mathrm{C}$, onde permaneceram por 72 horas (Torres e Marcos-Filho, 2001). Em seguida, as sementes foram submetidas ao teste de germinação, sendo avaliadas após o quarto dia de instalação e, os resultados, expressos em porcentagem de plântulas normais. Para fins de monitoramento do teste de envelhecimento acelerado, determinou-se o teor de água das sementes antes e após o período de incubação; emergência de plântulas em casa de vegetação, utilizando-se quatro repetições de 50 sementes por lote, distribuídas em bandejas multicelulares de isopor com células separadas, contendo substrato comercial, composto por casca de pinus, vermiculita, e fertilizante químico (informações obtidas junto ao fabricante). As bandejas foram mantidas entre $25 \mathrm{e}$ $30^{\circ} \mathrm{C}$, em casa de vegetação dotada de sistema de nebulização intermitente. As avaliações foram realizadas aos 21 dias após a semeadura; deterioração controlada, ajustando-se inicialmente o grau de umidade das sementes para três níveis diferentes (19; 21 e 24\%), através do método da atmosfera úmida (ROSSETTO et al., 1995), conduzido em caixas plásticas (gerbox), com amostras de $4,0 \mathrm{~g}$ de sementes, colocadas sobre a tela interna mediante a distribuição de uma camada simples. Estas caixas, tampadas e contendo $40 \mathrm{ml}$ de água, foram mantidas em incubadora, a $20^{\circ} \mathrm{C}$. Durante o umedecimento artificial, o grau de umidade das sementes foi monitorado, através de pesagens sucessivas, até a obtenção dos valores desejados; nesta ocasião, cada amostra foi colocada em recipiente de folha de alumínio, fechado hermeticamente, permanecendo por cinco dias em câmara fria $\left(8-10^{\circ} \mathrm{C}\right)$ para atingir o equilíbrio higroscópico. Em seguida, as sementes foram mantidas em banho-maria, a $45^{\circ} \mathrm{C}$, durante dois períodos ( 24 e 48 h). Posteriormente, os recipientes foram imersos rapidamente em água fria pra reduzir a temperatura, sendo instalado em seguida o teste de germinação (Powell, 1995); as interpretações do teste foram efetuadas aos quatro dias após a semeadura, computando-se a porcentagem de plântulas normais. Foi determinado, também, o grau de umidade das sementes após cada período de deterioração.

Utilizou-se delineamento estatístico inteiramente casualizado, com quatro repetições e as análises realizadas separadamente para cada teste. Os dados dos testes de germinação, primeira contagem de germinação, envelhecimento acelerado e emergência das plântulas foram transformados em arc sen $\sqrt{x / 100}$ e as médias comparadas pelo teste de Tukey, a $5 \%$.

\section{RESULTADOS E DISCUSSÃO}

Ocorreram diferenças significativas de qualidade entre os lotes avaliados através dos testes de vigor (Tabela 1). Os dados referentes ao grau de umidade das sementes foram semelhantes para os cinco lotes. Este fato é importante para a execução dos testes, considerando-se que a uniformização do teor de água das sementes é imprescindível para a padronização das avaliações e obtenção de resultados consistentes (MARCOS-FILHO, 1999). Assim, quanto à germinação e emergência de plântulas, as sementes mais úmidas, dentro de certos limites, germinam mais rapidamente. Por outro lado, o grau de umidade elevado prejudica o desempenho das sementes no teste de envelhecimento acelerado e pode favorecê-lo no teste de condutividade elétrica.

No teste de germinação observouse que houve melhor desempenho dos lotes 1 e 2, em relação aos lotes 3, 4 e 5 . Vale ressaltar que todos os lotes apresentaram percentagens média de plântulas normais superiores à mínima estabelecida para comercialização de sementes de maxixe, ou seja, $80 \%$ de germinação. Segundo Powell (1986), é importante e coerente a comparação de lotes de sementes que estejam, preferencialmente, situados na Fase I da curva de perda de viabilidade, pois ao atingir a Fase II, mesmo o teste de germinação (conduzido sob condições favoráveis) é capaz de detectar diferenças no potencial fisiológico das amostras avaliadas. Essa autora considera que a posição de 
Tabela 2. Dados médios obtidos no teste de deterioração controlada (DC) e no grau de umidade (GU) após os períodos de condicionamento, de sementes de cinco lotes de maxixe, cultivar Liso. Natal, EMPARN, 2004.

\begin{tabular}{|c|c|c|c|c|c|c|c|c|c|c|c|c|}
\hline \multirow{3}{*}{ Lote } & \multicolumn{6}{|c|}{ DC } & \multicolumn{6}{|c|}{ GU após DC } \\
\hline & \multicolumn{3}{|c|}{$24 \mathrm{~h}$} & \multicolumn{3}{|c|}{$48 \mathrm{~h}$} & \multicolumn{3}{|c|}{$24 \mathrm{~h}$} & \multicolumn{3}{|c|}{$48 \mathrm{~h}$} \\
\hline & $19 \%$ & $21 \%$ & $24 \%$ & $19 \%$ & $21 \%$ & $24 \%$ & $19 \%$ & $21 \%$ & $24 \%$ & $19 \%$ & $21 \%$ & $24 \%$ \\
\hline 1 & 92 a & $94 \mathrm{a}$ & 86 a & $90 \mathrm{a}$ & $84 a$ & $84 a$ & 18,9 & 20,8 & 24,2 & 18,7 & 21,0 & 23,7 \\
\hline 2 & $86 a b$ & $80 \mathrm{~b}$ & 91 a & $84 a b$ & 90 a & 89 a & 19,3 & 20,7 & 23,8 & 19,1 & 20,9 & 24,1 \\
\hline 3 & $82 \mathrm{~b}$ & 90 a & $83 b c$ & $70 \mathrm{bc}$ & 86 a & 86 a & 18,6 & 20,7 & 23,7 & 19,2 & 20,7 & 24,1 \\
\hline 4 & $80 \mathrm{~b}$ & $76 \mathrm{~b}$ & $70 \mathrm{~d}$ & $65 \mathrm{c}$ & $63 \mathrm{~b}$ & $63 \mathrm{~b}$ & 18,7 & 20,8 & 23,7 & 19,4 & 20,8 & 23,9 \\
\hline 5 & $80 \mathrm{~b}$ & $81 \mathrm{~b}$ & $79 \mathrm{~cd}$ & $70 \mathrm{bc}$ & $71 \mathrm{~b}$ & $70 \mathrm{~b}$ & 18,8 & 21.2 & 24,2 & 19,3 & 20,7 & 24,2 \\
\hline
\end{tabular}

*Médias seguidas pela mesma letra na coluna não diferem estatisticamente pelo teste de Tukey a 5\%.

cada lote dentro da Fase I determina seu nível de vigor. Nesse estudo, todos os lotes apresentaram germinação variando entre 85 e $96 \%$, estando situados, portanto, na Fase I da curva de perda de viabilidade da semente, caracterizada por ser relativamente longa e com poucas sementes mortas. Observa-se ainda que a porcentagem de germinação, de modo geral, superou a de emergência de plântulas, fato esperado, visto que o teste de germinação é conduzido sob condições ótimas.

Houve variação significativa entre os lotes quanto à emergência de plântulas em casa de vegetação. Os lotes 1 e 2 , foram superiores aos lotes $4 \mathrm{e}$ 5; por outro lado, o lote 4 apresentou menor porcentagem de emergência, não diferindo do lote 5 , enquanto que para o lote 3 foi observado valor intermediário. De acordo com Marcos-Filho (1999), o teste de emergência de plântulas constitui parâmetro indicador da eficiência dos testes para avaliação do potencial fisiológico de lotes de sementes. Portanto, verifica-se neste estudo essa eficiência em distinguir, com segurança, os lotes de alto e baixo vigor.

Os resultados do envelhecimento acelerado com solução salina e condutividade elétrica concordaram também com os resultados obtidos para os testes de germinação e emergência de plântulas em casa de vegetação, indicando a superioridade dos lotes 1 e 2; enquanto os lotes 4 e 5 foram confirmados como de baixo potencial fisiológico e o lote 3 de qualidade intermediária.

No teste de deterioração controlada (Tabela 2) observou-se que a combinação $24 \mathrm{~h} / 24 \%$ e temperatura de $45^{\circ} \mathrm{C}$, mostrou tendência compatível com a ordenação dos lotes obtida pelos testes de germinação, emergência de plântulas em casa de vegetação, envelhecimento acelerado com sal e condutividade elétrica, sendo considerada a mais promissora. Assim, classificou, de maneira geral, os lotes 1 e 2 como superiores; os lotes 4 e 5 como inferiores e, o lote 3 , como de qualidade intermediária, porém, tendendo para inferioridade. Esse resultado confirma os encontrados por diversos autores para sementes de hortaliças, dentre os quais podem-se citar os de Osman e George (1988) e Panobianco e Marcos-Filho (1998), com sementes de pimentão; os relatos da ISTA (1995), com beterraba e cenoura e Panobianco e Marcos-Filho (2001), com tomate. Esses autores afirmam que o ajuste do grau de umidade das sementes para $24 \%$ foi o mais adequado para a condução do teste. Por outro lado, Bhéring et al. (2000) verificaram, para sementes de pepino, que esse teor de água só se mostrou eficiente na condução do teste de deterioração controlada quando as sementes foram submetidas ao período de 48 horas de condicionamento em banho-maria.

As combinações utilizando o período de 48 horas e sementes com 21 e $24 \%$ de água e temperatura de $45^{\circ} \mathrm{C}$, foram menos discriminantes na separação dos lotes em diferentes níveis de vigor quando comparada com a combinação $24 \%$ l $45^{\circ} \mathrm{C} / 24 \mathrm{~h}$, o que não aconteceu com o trabalho de Bhéring et al. (2000) quando utilizaram sementes de pepino. Ainda com relação a esse aspecto, Bhéring et al. (2001a, b), verificaram que o teste de deterioração controlada foi mais adequado para sementes de melancia e berinjela, respectivamente, quando utili- zaram o período de 48 horas, a $41^{\circ} \mathrm{C}$ e sementes com $24 \%$ de água.

Para o grau de umidade das sementes, após o período em banho-maria, no teste de deterioração controlada (Tabela 2), pôde-se observar que as sementes permaneceram, praticamente, com o mesmo grau de umidade em relação ao início do teste. Assim, a técnica utilizada para a deterioração controlada mostrou-se eficiente, no sentido de manter constante o grau de umidade das sementes durante o decorrer do teste.

Desse modo, enfatiza-se a importância do uso de mais de um teste para determinar o vigor dos lotes de sementes, devido à influência dos métodos adotados e uso de situações específicas de estresse para estimar o comportamento relativo dos lotes em campo (TEKRONY; EGLY, 1977). Conclui-se que o período de 24 horas em banhomaria, a $45^{\circ} \mathrm{C}$, com ajuste do grau de umidade das sementes para $24 \%$ demonstrou eficiência, devendo ser considerado em programas de controle de qualidade de sementes de maxixe.

\section{LITERATURA CITADA}

BHÉRING, M.C.; BARROS, D.I.; DIAS, D.C.F.S. Aplicação do vigor de sementes de melancia pelos testes de envelhecimento acelerado e deterioração controlada. Informativo ABRATES, v.11, n.2, p.204, 2001a.

BHÉRING, M.C.; BARROS, D.I.; DIAS, D.C.F.S.; NUNES, H.V. Testes para avaliação da qualidade fisiológica de sementes de berinjela. Informativo ABRATES, v.11, n.2, p.203, 2001b.

BHÉRING, D.I.; DIAS, D.C.F.S.; GOMES, J.M; BARROS, D.I. Métodos para avaliação do vigor de sementes de pepino. Revista Brasileira de Sementes, v.22, n.2, p.171-175, 2000.

BRASIL. Ministério da Agricultura e Reforma Agrária. Regras para análise de sementes. Brasília: SNDA/DNDV/CLAV, 1992. 365 p. 
INTERNATIONAL SEED TESTING ASSOCIATION. Handbook of vigour test methods. 3. ed. Zürich, 1995. $117 \mathrm{p}$.

HAMPTON, J.G.; TEKRONY, D.M. Handbook of vigor test methods. Zürich: ISTA, 1995. $117 \mathrm{p}$ KRZYZANOWSKI, F.C.; VIEIRA, R.D. Deterioração controlada. In: KRZYZANOWSKI, F.C. VIEIRA, R.D; FRANÇA-NETO, J.B. (eds.). Vigor de sementes: conceitos e testes. Londrina: ABRATES, 1999. cap.6, p.1-8.

MARCOS-FILHO, J. Testes de vigor: importância e utilização. In: KRZYZANOWSKI, F.C. VIEIRA, R.D.; FRANÇA-NETO, J.B. (Eds.). Vigor de sementes: conceitos e testes. Londrina: ABRATES, 1999. cap.1, p.1-21.

MATTHEWS, S.; POWEEL, A.A. Controlled deterioration test. In: PERRY, D.A. (Ed.) Handbook of vigour test methods. 2.ed. Zürich: ISTA, 1987. p.49-56.

MENDONÇA, E.A.F.; RAMOS, N.P.; FESSEL, S.A. Adequação da metodologia do teste de deterioração controlada para sementes de brócolis (Brassica oleracea L.var. itálica. Revista Brasileira de Sementes, v.25, n.1, p.18-24, 2003.
OSMAR, O.A. GEORGE, R.A.T. Controlled deterioration as a vigor test for sweet pepper seed. Acta Horticulturae, n.218, p.109-114, 1988.

PANOBIANCO, M.; MARCOS-FILHO, J. Comparação entre métodos para avaliação da qualidade fisiológica de sementes de pimentão. Revista Brasileira de Sementes, v.20, n.2, p.306-310, 1998. PANOBIANCO, M.; MARCOS-FILHO, J. Envelhecimento acelerado e deterioração controlada em sementes de tomate. Scientia Agrícola, v.58, n.3, p.525-531, 2001.

POWELL, A.A. Cell membranes and seed leachate conductivity in relation to the quality of seed for sowing. Journal of Seed Technology, v.10, n.2, p.81-100, 1986.

POWELL, A.A. The controlled deterioration test. In: VAN DE VENTER, H.A. (Ed.). Seed vigour testing seminar. Copenhagen: ISTA, 1995. p.73-87.

POWELL, A.A.; MATTHEWS, S. Evaluation of controlled deterioration: a new vigour test for small seeds vegetables. Seed Science and Technology, v.9, n.2, p.633-640, 1981.

ROSSETTO, C.A.V.; FERNANDEZ, E.M.; MARCOS-FILHO, J. Metodologias de ajuste do grau de umidade e comportamento das sementes de soja no teste de germinação. Revista Brasileira de Sementes, v.17, n.2, p.171-178, 1995.
THORNTON, J.M.; POWELL, A.A. Short-term aerated hydration for the improvement of seed quality in Brassica oleracea L. Seed Science Research, v.2, n.1, p.41-49, 1992.

TORRES, S.B. Métodos para avaliação do potencial fisiológico de sementes de melão. Piracicaba: 2002. 103 f. (Tese doutorado) ESALQ, USP, Piracicaba.

TORRES, S.B.; CASEIRO, R.F.; RODO, A.B.; MARCOS-FILHO, J. Testes de vigor em sementes de maxixe (Cucumis anguria L.) com ênfase ao teste de condutividade elétrica. Revista Brasileira de Sementes, v.20, n.2, p.480-483, 1998.

TORRES, S.B.; MARCOS-FILHO, J. Teste de envelhecimento acelerado em sementes de maxixe (Cucumis anguria L.). Revista Brasileira de Sementes, v.23, n.2, p.108-112, 2001.

TEKRONY, D.M.; EGLY, D.B. Relationship between laboratory índices of soybean seed vigor and field emergence. Crop Science, v.17, n.4, p.573-577, 1977. 